\title{
The Impact of a Community Pharmacy-Based Coaching Program on Patient Confidence and Lifestyle
}

\author{
Feng Chang1,2, Nishi S. Gupta1, Laura Smith², Dan Stringer ${ }^{2}$ \\ ${ }^{1}$ School of Pharmacy, University of Waterloo, Waterloo, Canada \\ ${ }^{2}$ Gateway Rural Health Research Institute, Seaforth, Canada \\ Email: feng.chang@uwaterloo.ca
}

Received 7 April 2014; revised 28 May 2014; accepted 13 June 2014

Copyright (C) 2014 by authors and Scientific Research Publishing Inc.

This work is licensed under the Creative Commons Attribution International License (CC BY). http://creativecommons.org/licenses/by/4.0/

(c) (i) Open Access

\begin{abstract}
Objective: Like their urban counterparts, rural populations are experiencing increased health risks due to chronic disease. However, disease management is more problematic due to isolation, increased difficulty in getting to medical appointments, and reduced numbers of medical personnel. We undertook a pilot study to investigate the feasibility and utility of health coaching for rural residents with type 2 diabetes mellitus (DM2) from a local pharmacy. Methods: Using the pharmacy database to identify qualified individuals, a nursing student recruited four individuals aged 40 79, with a history of DM2 of 3 - 15 years, to participate in the pilot project. Individual in-person interviews were conducted to identify specific goals to effectively self-manage their condition and to rate their confidence in their ability to fulfill these goals. Three monthly sessions were held to review and update goals, and to record blood pressure, waist circumference and weight measurements. Results: At the end of the study, all four achieved success in reaching and maintaining their personal dietary and physical activity goals. Significantly, all participants expressed increased confidence in their ability to self-manage their diabetes after health coaching. Conclusion: The provision of health coaching services from local pharmacies has potential to support rural clients in chronic disease management in medically under-serviced rural areas.
\end{abstract}

\section{Keywords}

Diabetes Mellitus, Health Coaching, Pharmacy

\section{Introduction}

Globally, the direct costs of diagnosis and treatment of the 347 million people with type 2 diabetes mellitus

How to cite this paper: Chang, F., Gupta, N.S., Smith, L. and Stringer, D. (2014) The Impact of a Community Pharmacy-Based Coaching Program on Patient Confidence and Lifestyle. Open Journal of Preventive Medicine, 4, 499-503. 
(DM2) [1] consumed 11.6\% of healthcare budgets in 2010 (US \$376 billion) [2]. Since the prevalence of DM2 increases from $<1 \%$ in children to $>25 \%$ in adults aged $<70$ [3], these figures are projected to mushroom in the next twenty years. Poor diet, physical inactivity, smoking, and high alcohol consumption are major contributors to the development and progression of type 2 diabetes [4]. According to the World Health Organization, up to $80 \%$ of type 2 diabetes cases are preventable or manageable through modifying behavioral risk factors [5]. Thus, forward-looking healthcare agencies are motivated to investigate cost-effective approaches to help individuals prevent onset of diabetes or self-manage their disease by adherence to medication and maintenance of healthy lifestyle behaviors. Unfortunately, simply educating diabetic patients on self-management techniques does not improve clinical outcomes [6].

Health coaching is the process of guiding individuals toward change through goal-setting, behavioral modification, and identification of challenges in a collaborative setting [7]. In contrast with traditional directive models of care, this patient-centered approach fosters a collaborative environment in which the coaching personnel supports, guides, listens, and provides information in a non-judgmental manner [7]. Health coaching allows patients to participate actively and confidently in their own care by offering the necessary knowledge, skills, and tools, enhancing the likelihood of achieving self-identified lifestyle goals.

Several previous studies incorporating health coaching in the disease management process have reported improved health outcomes and medication adherence [8]-[10]. However, very few such studies have been conducted in a community pharmacy setting.

Health coaching requires an investment of time that many primary practitioners cannot afford, but highly trained community pharmacists whom already have established relationships with their clientele have an opportunity to fulfill this role. The Gateway Rural Health Research Institute collaborated with the University of Waterloo School of Pharmacy to introduce a pharmacist-led pilot health-coaching program for adults with DM2 to manage diabetes.

\section{Methods}

The Office of Research Ethics at the University of Waterloo approved the pilot health-coaching program. The program was established in a collaborating community pharmacy in rural Ontario, Canada from May-August 2011. Adult patients visiting the pharmacy were invited to participate if they had medications for diabetes on their medication profiles.

Consultations were conducted by a nursing student supervised by a pharmacist trained in health coaching to document patient demographics, blood pressure (BP), waist circumference (WC), blood glucose levels (BG), body weight (W), and lifestyle behaviors such as diet, smoking, and exercise. Participants were also encouraged to discuss any concerns they had about diabetes and note resources they currently use for managing their diabetes. The pharmacist and nursing student worked collaboratively with participants to develop a plan with personalized goals and timelines focused on behavioral improvements toward healthy eating and physical activity. Participants rated the importance of their goals and their confidence in being able to achieve their goals. If needed, participants were provided with glucometers, pedometers, and information to reinforce their motivation.

Three monthly in-person follow-up sessions were scheduled to discuss progress in achieving goals and address obstacles and to provide guidance on continuing, modifying, or creating new behavioral goals. Clinical measurements were repeated at each visit. A telephone follow-up was conducted six months later to assess progress, maintenance of behavioral goals, and outlook and to gather feedback about the program.

\section{Results}

Four individuals aged 40 - 79 with DM2 provided written consent to participate. The participants' demographics and clinical measurements are reported in Table 1 . However, the focus of this program was to assess the effect of health coaching on the participant's ability to develop achievable goals and maintain implemented changes in the long term. The goals were specific to each participant and reflected their personal values. Progress was reported at follow-up sessions and when warranted, unrealistic goals were re-set. All experienced success in achieving goals such as skipping dessert, walking 10,000 steps, reducing carbonated drink consumption, etc. that were maintained at the six-month follow-up.

All reported increased confidence in their ability to achieve self-set goals and in their perception of the importance of their goals (Figure 1). Participants agreed unanimously on the value of the program and stated that they 
Table 1. Participant characteristics at the beginning and end of the health coaching program.

\begin{tabular}{|c|c|c|c|c|c|c|c|c|}
\hline & \multicolumn{2}{|c|}{$\mathbf{A}$} & \multicolumn{2}{|c|}{ B } & \multicolumn{2}{|c|}{ C } & \multicolumn{2}{|c|}{ D } \\
\hline Sex & \multicolumn{2}{|c|}{ Male } & \multicolumn{2}{|c|}{ Female } & \multicolumn{2}{|c|}{ Male } & \multicolumn{2}{|c|}{ Male } \\
\hline Age (years) & \multicolumn{2}{|c|}{79} & \multicolumn{2}{|c|}{52} & \multicolumn{2}{|c|}{74} & \multicolumn{2}{|c|}{40} \\
\hline Smoking (years) & \multicolumn{2}{|c|}{30} & \multicolumn{2}{|c|}{13} & \multicolumn{2}{|c|}{20} & \multicolumn{2}{|c|}{10} \\
\hline Diagnoses of DM2 (years) & \multicolumn{2}{|c|}{3} & \multicolumn{2}{|c|}{12} & \multicolumn{2}{|c|}{19} & \multicolumn{2}{|c|}{5} \\
\hline Measures & May & August & May & August & May & August & May & August \\
\hline Blood pressure (mmHg) & $130 / 75$ & $128 / 83$ & $117 / 72$ & $108 / 64$ & $161 / 70$ & $149 / 62$ & $130 / 90$ & $137 / 95$ \\
\hline Weight (pounds) & 219.2 & 217.8 & 256.4 & 258.4 & 204.2 & 202.4 & 290 & 283 \\
\hline Waist (inches) & 43.5 & 43 & 46 & 45.5 & 40.5 & 40.5 & 49 & 49 \\
\hline Blood glucose (mmol/L) & 9 & 7.1 & 10.2 & 5.9 & 6.7 & 4.2 & 13.1 & 6.9 \\
\hline
\end{tabular}

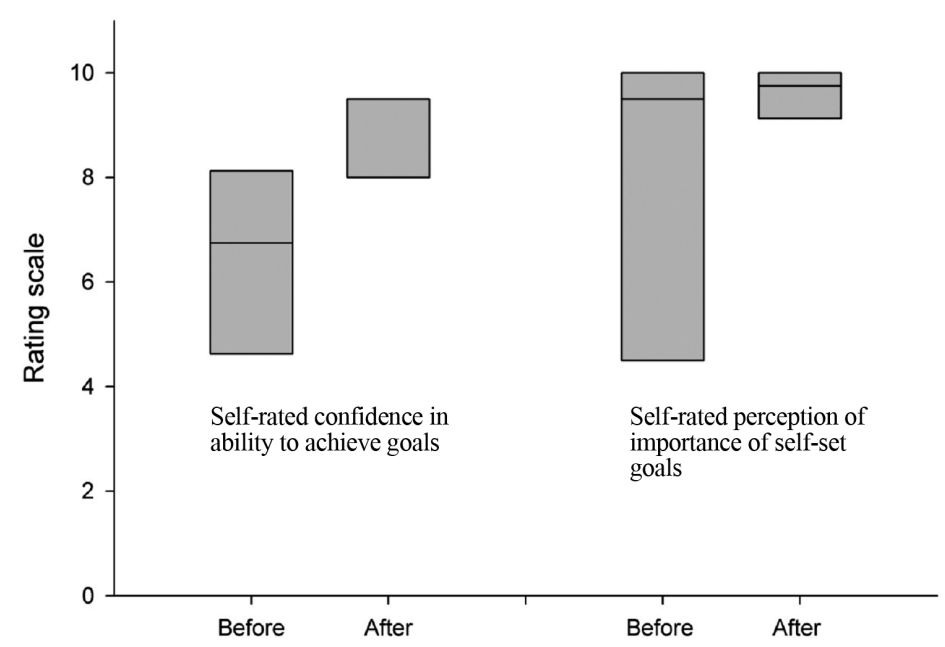

Figure 1. Box-plot of self-rated confidence and importance of goals at the beginning and end of the health coaching program.

would participate in similar programs offered at community pharmacies. While one patient did note a perceived overlap of the informational services offered in this program with other resources in the community, all found the program to be constructive. One participant commented the health coaching was instrumental in reinforcing the necessity of adopting healthy lifestyle behavior. Another patient appreciated the encouraging nature of the program and described becoming much more motivated as a result of participating. Even at 6 months post intervention, patients continued to use and apply the knowledge they attained during the program.

\section{Discussion}

Geographically isolated patients experience greater difficulty managing chronic disease due to lack of support, which contributes to non-adherence to medical protocols [11] [12] and may result in exacerbated disease. One of the main goals of the coaching program was to engage and support participants in taking personal responsibility to make sustainable long-term changes in behavior. The participants' self-perceived ability to take on this responsibility was an important aspect of motivating participants to act. Health coaching was instrumental in reinforcing the necessity of adopting healthy lifestyle behavior and resulted in enhanced participant motivation, as shown by their adherence to their goals six months later. The outcomes demonstrate targeting limited resources to motivated adults supports their transition to empowerment over their disease.

The emergence of self-management in chronic diseases marks a crucial paradigm shift from the traditional directive model of care to a more collaborative, patient-centered one. Health coaching targets behavioral changes using individually tailored solutions to develop and attain health-promoting goals. Preliminary data from this pilot program suggest that diabetes-coaching programs in a community pharmacy setting can effectively aid pati- 
ents to establish and sustain healthy behavioral habits. This is promising as lifestyle behaviors are considered major contributors to chronic conditions such as type 2 diabetes [13] [14]. This pilot was successful in increasing participant confidence in their ability to achieve their individual goals and enhanced their outlook on the importance of achieving their self-set goals.

The pilot program highlighted hurdles to implementation that require further address. The current study faced obstacles with recruitment and perceived overlap with other resources in the community. Recruitment difficulties may have been due to the method employed, which reached only a limited number of eligible patients. To increase recruitment, study invitations may be mailed to all eligible patients and flyers describing the study can be posted in pharmacies, grocery stores, or community centers. The retail pharmacy setting of the program also posed some challenges. Due to the fast-paced environment, investigators and staff did not always have sufficient time. Furthermore, some patients did not perceive the pharmacy as a learning setting and were unused to sitting down for a personal meeting in a retail pharmacy. This can be overcome by ensuring the presence of at least one designated healthcare worker whose primary focus is the diabetes program.

Community pharmacists are highly accessible healthcare professionals as they regularly see patients for medication management and they are readily available even in small rural communities. This study showed that community pharmacists could provide support to improve patients' self-perceived ability to manage their disease-a role currently largely unfilled under the traditional healthcare model.

\section{Acknowledgements}

The authors would like to acknowledge the generous support provided by the pharmacists and staff at the community pharmacy.

\section{References}

[1] Danaei, G., Finucane, M.M., Lu, Y., Singh, G.M., Cowan, M.J., Paciorek, C.J., Lin, J.K., Farzadfar, F., Khang, Y.H., Stevens, G.A., Rao, M., Ali, M.K., Riley, L.M., Robinson, C.A. and Ezzati, M. (2011) National, Regional, and Global Trends in Fasting Plasma Glucose and Diabetes Prevalence Since 1980: Systematic Analysis of Health Examination Surveys and Epidemiological Studies with 370 Country-Years and 2.7 Million Participants. Lancet, 378, 31-40. http://dx.doi.org/10.1016/S0140-6736(11)60679-X

[2] Zhang, P., Zhang, X., Brown, J., Vistisen, D., Sicree, R., Shaw, J. and Nichols, G. (2010) Global Healthcare Expenditure on Diabetes for 2010 and 2030. Diabetes Research and Clinical Practice, 87, 293-301. http://dx.doi.org/10.1016/j.diabres.2010.01.026

[3] Public Health Agency of Canada (2011) Diabetes in Canada: Facts and Figures from a Public Health Perspective.

[4] Sahay, B.K. and Sahay, R.K. (2002) Lifestyle Modification in Management of Diabetes Mellitus. Journal of Indian Medical Association, 100, 178-180.

[5] World Health Organization (2008) 2008-2013 Action Plan for the Global Strategy for the Prevention and Control of Noncommunicable Diseases. WHO, Geneva.

[6] Clement, S. (1995) Diabetes Self-Management Education. Diabetes Care, 18, 1204-1214.

[7] Bennett, H.D., Coleman, E.A., Parry, C., Bodenheimer, T. and Chen, E.H. (2010) Health Coaching for Patients with Chronic Illness. Family Practice Management, 17, 24-29.

[8] Olsen, J.M. and Nesbitt, B.J. (2010) Health Coaching to Improve Healthy Lifestyle Behaviors: An Integrative Review. American Journal of Health Promotion, 25, e1-e12. http://dx.doi.org/10.4278/ajhp.090313-LIT-101

[9] Newnham-Kanas, C., Gorczynski, P., Morrow, D. and Irwin, J.D. (2009) Annotated Bibliography of Life Coaching and Health Research. International Journal of Evidence Based Coaching and Mentoring, 7, 39-103.

[10] Melko, C.N., Terry, P.E., Camp, K., Xi, M. and Healey, M.L. (2010) Diabetes Health Coaching Improves Medication Adherence: A Pilot Study. American Journal of Lifestyle Medicine, 4, 187-194. http://dx.doi.org/10.1177/1559827609351131

[11] Steinhardt, M.A., Mamerow, M.M., Brown, S.A. and Jolly, C.A. (2009) A Resilience Intervention in African American Adults with Type 2 Diabetes: A Pilot Study of Efficacy. The Diabetes Educator, 35, 274-284. http://dx.doi.org/10.1177/0145721708329698

[12] Dimatteo, M.R. (2004) Variations in Patients’ Adherence to Medical Recommendations: A Quantitative Review of 50 Years of Research. Med Care, 42, 200-209. http://dx.doi.org/10.1097/01.mlr.0000114908.90348.f9

[13] Woolf, S.H. (2009) A Closer Look at the Economic Argument for Disease Prevention. JAMA, 301, 536-538. 
http://dx.doi.org/10.1001/jama.2009.51

[14] Hoerger, T.J., Hicks, K.A., Sorensen, S.W., Herman, W.H., Ratner, R.E., Ackermann, R.T., Zhang, P. and Engelgau, M.M. (2007) Cost-Effectiveness of Screening for Pre-Diabetes among Overweight and Obese US Adults. Diabetes Care, 30, 2874-2879. http://dx.doi.org/10.2337/dc07-0885 
Scientific Research Publishing (SCIRP) is one of the largest Open Access journal publishers. It is currently publishing more than 200 open access, online, peer-reviewed journals covering a wide range of academic disciplines. SCIRP serves the worldwide academic communities and contributes to the progress and application of science with its publication.

Other selected journals from SCIRP are listed as below. Submit your manuscript to us via either submit@scirp.org or Online Submission Portal.
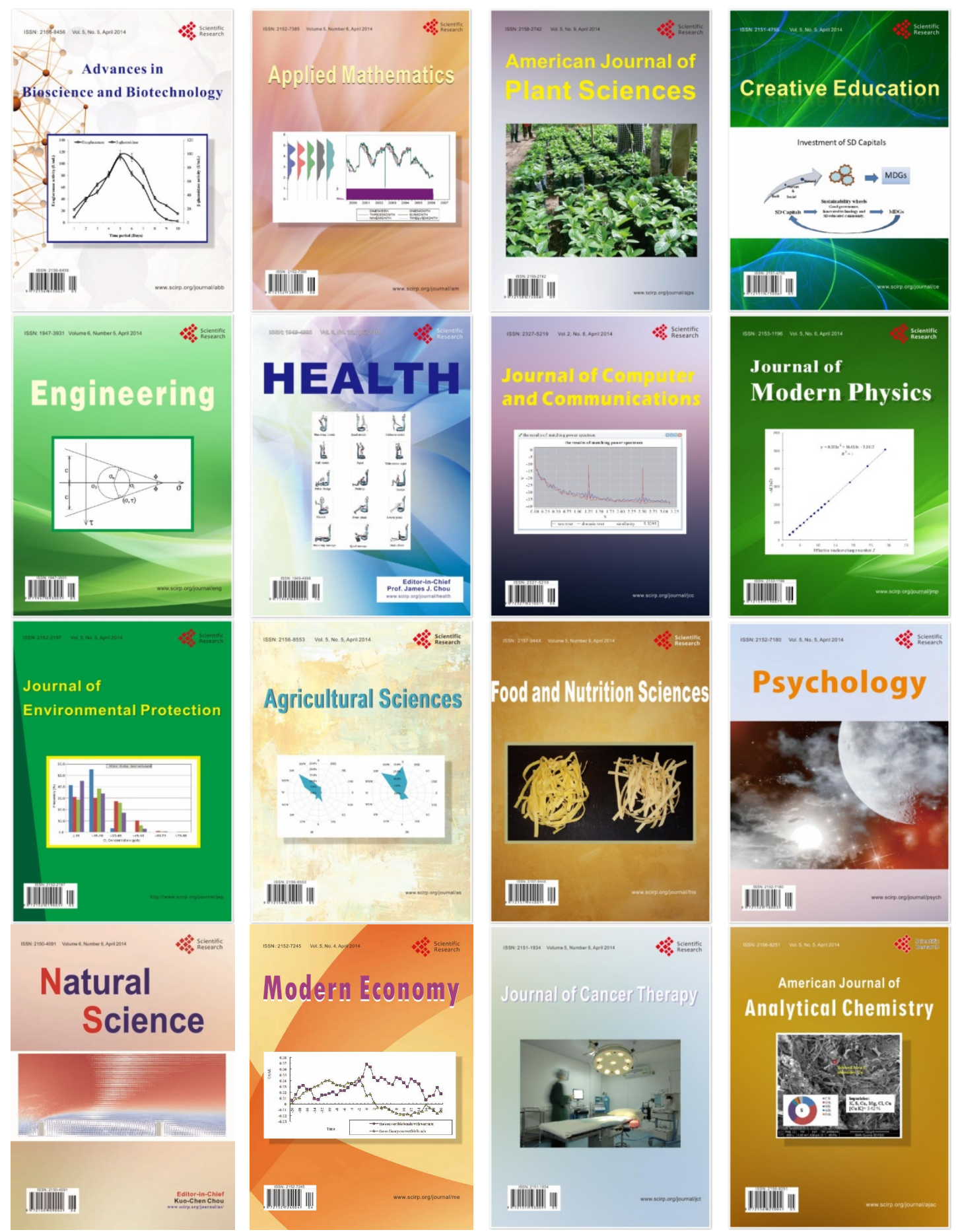